\title{
Mbi administrimin e Tokave të Liruara
}

\author{
Myrteza Sharra
}

Periudha ndërmjet dy Luftërave të mëdha Botërore, karakterizohet nga përpjekja e vazhdueshme e mbretërisë serbo-kroate-sllovene për të ndryshuar përkatësinë e këtyre trevave me mënyra nga më të ndryshmet. ${ }^{1}$ Ekzistonin plane shtetërore për shpërnguljen e popullsisë shqiptare nga këto treva dhe zëvendësimin e tyre me kolonë serbo-malazezë. ${ }^{2}$ Reforma agrare ishte një nga metodat që i shërbente më së miri kësaj politike, por qëndresa e shqiptarëve ishte e madhe dhe bëri që këto plane të dështonin duke mos u arritur sllavizimi i këtyre territoreve. Më pas shpërngulja e detyruar drejt Turqisë e popullsisë së Kosovës, me motivacionin që ishin turq të mbetur nga koha e Perandorisë Osmane, ishte një tjetër metodë. ${ }^{3}$ Pas firmosjes së marrëveshjes jugosllavo-turke, një numër i madh shqiptarësh u shpërngulën. Shqiptarët në periudhën e dy luftërave thuajse nuk gëzonin as të drejtat më minimale të një kombësie brenda një vendi, në bazë të atyre çka shprehte Lidhja e Kombeve.

Para fillimit të Luftës së Dytë Botërore, më 7 prill 1939 Italia pushton zyrtarisht Shqipërinë. Me pushtimin e Shqipërisë italianët menjëherë vendosën një qeveri nën ndikimin e tyre. Tanimë Shqipëria ishte pjesë e Komunitetit Perandorak të Romës. Më 6 prill 1941 Gjermania dhe Italia pushtojnë Jugosllavinë. Kapitullimi i Jugosllavisë krijoi një gjendje të re në Ballkan edhe për trevat shqiptare që ishin brenda shtetit jugosllav. Ndarja e territoreve të Jugosllavisë midis Italisë, Gjermanisë dhe Bullgarisë solli bashkimin e zonës italiane të pushtimit me pjesën e pushtuar të Shqipërisë.

1 Muhamet Shatri, Kosova në Luftën e Dytë Botërore 1941-1945, Tiranë, Toena, 1997, f. 8.

2 AQSH, F. 14/APSTR, V. 1977, D. 522 f. 13-18.

3 Po aty. 


\section{Albanon}

\section{Revistë kulturore}

Bashkimi i trevave të Kosovës dhe trojeve të tjera të ish-Jugosllavisë me shtetin shqiptar nuk u bë i plotë pra, sipas parimit etnik. Një pjesë e territoreve mbetën jashtë administrimit të shtetit shqiptar.

Ndarja e parë e këtyre territoreve u bë në bazë të marrëveshjes së arritur më 21-22 prill 1941 midis ministrit të Jashtëm të Gjermanisë, Ribentrop dhe ministrit të Jashtëm të Italisë Galeaco Ciano; ndarja u bë midis Italisë, Gjermanisë dhe Bullgarisë. ${ }^{4}$ Italia mori pjesën më të madhe të territoreve: Prishtinën, Ferizajn, Gjilanin, Kamenicën, Rrafshin e Dukagjinit me Pejën, Gjakovën, Prizrenin; territoret në veri Tuzin, Ulqinin, Plavën, Gucinë; territoret në lindje Tetovën, Strugën, Kërçovën, Gostivarin, Dibrën. ${ }^{5}$

Më 29 qershor 1941, doli dekreti për ushtrimin e pushtetit civil të qeverisë shqiptare në Strugë, Dibër e Kosovë. ${ }^{6}$

Në takimin me Xhaferr Devën, i dërguari i Ministrisë së Jashtme Gjermane për Ballkanin, H.Neubacher i kishte siguruar këtij se Gjermania do të hynte në territorin shqiptar si një ushtri mike që kishte për qëllim të mbante pozicionet duke mos lejuar një zbarkim të aleatëve në këtë pjesë të territorit dhe do të njihte një qeveri shqiptare të formuar nga vetë shqiptarët dhe sigurisht sovranitetin e saj.

Pas kapitullimit zyrtar të Italisë, forcat gjermane hynë në territorin e Shqipërisë dhe u vendosën në pikat strategjike të vendit. Që në fillim, ata deklaruan se kishin ardhur si ushtri mike dhe jo si pushtuese. Gjen. Maj. Besell, më 14 shtator deklaroi se i linte dorë të lirë shqiptarëve për të vendosur fatin e tyre politik. Pushteti iu dorëzua brenda ditës Komitetit Ekzekutiv të Përkohshëm, i dalë ky nga një komitet që nënshkroi Deklaratën e Pavarësisë. ${ }^{7}$ Në deklaratë ndër të tjera thuhej se për t'i prerë hovin "anarkisë së krijuar me ndryshimin e situatës", duke besuar fetarisht në ardhmërinë e vendit dhe në "të drejtat si komb i lirë dhe i pavarur", vendosej rishpallja e pavarësisë, legalizimi i së cilës do të bëhej nga një vendim i Kuvendit. ${ }^{8} \mathrm{U}$ deklarua rrëzimi i qeverisë Libohova dhe zëvendësimi i saj me një komitet të përkohshëm i cili do të kryente detyrat ekzekutive dhe do përgatiste zgjedhjet. Ky komitet veproi nga 14 shtator -4 nëntor 1943 .

4 Historia e Popullit shqiptar IV, Tiranë: Toena, 2009, f. 129.

5 Lefter Nasi, Ripushtimi I Kosovës shtator 1944-korrik 1945, Tiranë: Akademia e Shkencave e Republikës së Shqipërisë, Instituti i Historisë, 1994, f. 10

6 Kastriot Dervishi, Historia e Shtetit Shqiptar 1912-2005, Tiranë: Shtëpia Botuese 55,2006, f. 450.

7 Po aty, f. 495.

8 Po aty. 
Si ishte premtuar dhe më herët, Gjermania, më 24 shtator 1943, nëpërmjet të dërguarit të posaçëm për Ballkanin, njohu Pavarësinë e Shqipërisë, ${ }^{9}$ por me terma të tjerë, duke përdorur emërtimin "sovranitet dhe neutralitet relativ", gjë që në fakt linte përshtypjen e një pavarësie fiktive.

Më 1 tetor u mbajtën zyrtarisht zgjedhjet dhe vetëm Korça, në pamundësi për t’i zhvilluar zgjedhjet brenda kësaj date, i caktoi përfaqësuesit e saj. Më 16 tetor Asambleja apo "Kuvendi kombëtar" hapi punimet. Më 22 tetor, Asambleja miratoi dhe dekretoi disa vendime ku ndër të tjera ishin:

- Shfuqizimin e “bashkimit personal” me Italinë,

- $\quad$ abrogimin e të gjithë ligjeve që binin në kundërshtim me vendimet e 22 tetorit,

- caktimin e institucioneve të Këshillit të Naltë të Regjencës duke marrë parasysh modelin e Kongresit të Lushnjës,

- rifuqizimin e Statutit Themeltar të Mbretërisë Shqiptare të 1928.

Më 25 tetor Kuvendi Kombëtar zgjodhi si anëtarë të Këshillit të Naltë, Mehdi Frashërin, Lef Nosin, Fuad Dibrën dhe padër Anton Harapin. ${ }^{10}$ Këshilli i Naltë ia caktoi detyrën e formimit të qeverisë Rexhep Mitrovicës.

Qeveria e re e formuar, me në krye Rexhep Mitrovicën kishte një përfaqësim nga të gjitha krahinat e ndryshme të vendit, ku binin në sy tre ministra nga Kosova. ${ }^{11}$ Po ashtu si italianët edhe gjermanët i dhanë një mbështetje të madhe nacionalizmit vendas sidomos atij në Troje. Në marrëveshjen e arritur më herët me Xhaferr Devën, para kapitullimit italian, përfaqësuesi për Europën Juglindore i Ministrisë së Jashtme të Gjermanisë, Dr. H. Neubacher kishte dhënë siguri për:

1. bashkimin e krahinave shqiptare të Kosovës dhe territoreve të tjera që gjendeshin nën okupacionin italian, me shtetin shqiptar të 1913,

2. vazhdimin e mbajtjes së statusit të deritanishëm për katër nënprefekturat të banuara me shumicë shqiptare të Mitrovicës, Pazarit të Ri, Vuçiternit dhe Podujevës, që gëzonin autonomi shqiptare brenda shtetit serb,

9 Po aty.

10 Historia e Popullit, 84-85.

11 Kastriot Dervishi, Historia e Shtetit, 505. 


\section{Albanon}

Revistë kulturore

3. Gjermania do të bënte një shpallje zyrtare, ku do të njihte shkëputjen e shtetit shqiptar nga Perandoria Italiane dhe pavarësinë e tij,

4. Gjermania, për shkak të luftës do të vendoste trupat e saj në Shqipëri, duke premtuar tërheqjen e plotë të tyre pas përfundimit të luftës. ${ }^{12}$

Pra do të njihej sovraniteti i shtetit të ri shqiptar me një territor shumë më të gjerë se sa Shqipëria e 1913, ku pjesa më e madhe e Kosovës dhe Maqedonisë Perëndimore do të bashkoheshin me shtetin amë. Ashtu dhe si kishin premtuar më herët, në fund të shtatorit, gjermanët njohën zyrtarisht Shqipërinë si një shtet i pavarur dhe neutral. ${ }^{13} \mathrm{U}$ deklarua se autoritetet gjermane njihnin "neutralitetin relativ shqiptar". ${ }^{14}$

Në të gjitha qytetet shqiptare të Kosovës dhe Maqedonisë Perëndimore, gjatë kohës së pushtimit italian të këtyre territoreve, administrata kishte qenë thuajse tërësisht shqiptare. Politika e nisur nga Italia dhe e vazhduar më me vendosmëri nga Gjermania në këto territore, ishte qartas në mbështetje të elementeve nacionaliste dhe antikomuniste. Ky ishte dhe qëndrimi i pjesës më të madhe të popullsisë, pasi ideologjia komuniste identifikohej me nacionalizmin serb, i cili kishte lënë gjurmë të thella në ndërgjegjen e shqiptarëve të trojeve, të cilët i shihnin serbët si armiq të papajtueshëm. ${ }^{15}$

Një raport komunist i 1943 thekson: "Lëvizja në Kosovë është shumë e dobët, pothuaj e vdekur. Është e izoluar plotësisht nga masat shqiptare. Midis masave shqiptare, komunistët konsiderohen si njerëz që i janë shitur serbëve" ${ }^{16}$ Duhet theksuar se ndikimi italian ne këto zona ishte mjaft i dobët; me gjithë politikën e ndjekur nga Italia, ai nuk u arrit të ishte në pritshmëritë e duhura. Kjo vërehet më vonë, pasi një pjesë e mirë e popullsisë së këtyre zonave u hodhën në krahun e komunistëve.

Organizimi i administratës, përkatësisht i pushtetit civil në Kosovë e trevat e tjera, iu ngarkuan Komisariatit të Lartë Civil, i cili drejtohej nga Fejzi Alizoti dhe mori detyrën në gusht të $1941 .{ }^{17}$ Në kompetencat e Komisariatit të Lartë ishte formimi i prefekturave dhe nënprefekturave. ${ }^{18}$ Në gusht të 1941, këto

12 Rexhep Krasniqi, Xhaferr Deva, Jeta dhe veprimtaria, (New York: 1963), 42.

13 Noel Malcolm, Kosova: Një histori e shkurtër, Prishtinë: Koha Ditore, 2001, f. 317.

14 Muhamet Shatri, Kosova, 32.

15 Shyqyri Hysi, Histori e Trojeve dhe Diasporës Shqiptare, Tiranë: SHBLU, 2007, f. 108.

16 Noel Malcolm, Kosova: Një histori, f. 314.

17 Muhamet Shatri, Kosova..., f. 18.

18 Historia e Popullit, f. 130. 
treva u ndanë në tri prefektura me qendër Prizren, Prishtinë dhe Dibër. Më 22 shtator u dekretua dhe formimi i prefekturës së Pejës. ${ }^{19}$ Pas kapitullimit të Italisë, kjo mënyrë ndarjeje vazhdoi të ekzistonte dhe vetëm në gusht të $1944 \mathrm{u}$ dekretua formimi i prefekturës së Tetovës. ${ }^{20}$ Prefekturat e formuara përbëheshin nga disa nënprefektura. Prefektura e Prizrenit përfshinte në kuadrin e saj katër nënprefektura (Suharekë, Gjakovë, Rahovec dhe Dragash). Prefektura e Prishtinës përfshinte dy nënprefektura, atë të Gjilanit dhe atë të Ferizajt. Prefektura e Pejës përbëhej nga gjashtë nënprefektura (Plavë, Guci, Rozhajë, Tutini, Istogu dhe Drenica). Prefektura e Dibrës përfshinte nënprefekturat e Dibrës, Kërcovës, Rostushës, Gostivarit dhe në fillim të Tetovës. ${ }^{21}$ Pas formimit të prefekturës së Tetovës një pjesë e territoreve që ishin nën administrimin e prefekturës së Dibrës, i kaluan asaj.

Në këtë linjë, organizimi administrativ u vazhdua edhe në këtë periudhë, pasi kjo kishte qenë efikase dhe kishte dhënë rezultat (me gjithë vështirësitë që i paraqiteshin duke filluar që nga mospërvoja e nëpunësve deri tek niveli i ulët arsimor). Tashmë gjendja kishte ndryshuar, pasi arsimi në Kosovë e në treva kishte mëse dy vjet që zhvillohej.

Ndryshe nga më parë, popullsia mund të mësonte gjuhën amtare, gjë e cila në Jugosllavi thuajse ishte e mohuar kategorikisht. Arsimi në gjuhën shqipe në këto treva ndikoi shumë në forcimin e vetëdijes kombëtare. Gjithashtu e gjithë politika e ndjekur në Troje, solli edhe rizgjimin e identitetit shqiptar te shqiptarët ortodoksë të cilët në regjistrimet e bëra nga administrata jugosllave ishin kategorizuar si serbë. Tanimë ata kërkonin regjistrimin si shqiptarë të besimit ortodoks. ${ }^{22}$

Që në fillim të pushtimit italian dhe me hapjen e shkollave, u pa nevoja për mësues në Kosovë e në treva. Mësuesit u emëruan nga Shqipëria dhe kryesisht nga qytetet e Elbasanit, Korçës, Krujës Tiranës, Shkodrës etj. Nevoja për mësues vazhdonte të ishte evidente, dhe pse tanimë me ngritjen e Normales së Prishtinës, një pjesë mësuesish formoheshin aty. Por numri më i madh i arsimtarëve vazhdonte të vinte nga qytetet e përmendura, pasi nevoja ishte tejet e madhe. Në dëshmitë që kanë lënë shumë mësues apo nxënës të asaj periudhe, na jepen qartë vështirësitë, por edhe dëshira e madhe e njerëzve për të mësuar gjuhën shqipe.

19 Po aty,f. 130-131.

20 Poaty.

21 Muhamet Shatri, Kosova, f. 18-19.

22 AQSH F. 410, D. 122, V. 1942, fl. 17. 


\section{Albanon}

\section{Revistë kulturore}

Njerëzit ishin aq entuziastë sa merrnin përsipër të ndërtonin vetë shkollat, vetëm e vetëm që fëmijët e tyre të mos mbeten në errësirë. ${ }^{23}$ Pritja e mirë e arsimtarëve në Troje tregohet dhe nëpërmjet raporteve drejtuar Ministrisë së Arsimit ku në një raport ndër të tjera thuhet: “...në çdo qendër e krahinë, pjestarët dhe mësuesit e këtij misioni kanë qenë të pritur mirë dhe me shumë entuziazëm." ${ }^{24}$ Kënaqësia e popullsisë dhe e brezit të ri për arsimin e gjuhës shqipe ishte prezente, çka solli një ecuri më të stabilizuar të arsimit. ${ }^{25}$ Shumica e godinave shpesh ishin të amortizuara dhe popullsia vendase, në mënyrë vullnetare merrte përsipër ndërtimin e një godine të re, kjo ndodhte kryesisht në krahinat që ishin të pasura dhe nuk e kërkonin ndihmën e ministrisë. ${ }^{26}$ Bazat e arsimit në këto krahina ishin hedhur që në 1941 dhe tanimë kishte një vijuesshmëri në shkollë të fëmijëve. Problemi qëndronte te mosha më e madhe, pasi thuajse ishin të gjithë analfabetë.

Mungesa e shkollave shqipe në Jugosllavi, shtypja nga jugosllavët duke mos lejuar që të shkolloheshin shqiptarët, duke shmangur kështu dhe krijimin e një klase intelektuale shqiptare, kishin lënë pasojat e tyre. Lufta kundër analfabetizmit te të rriturit do të vazhdohej në formën e kurseve. Gjatë viteve 1943-1944 forma themelore për arsimin e të rriturve mbeten kurset. ${ }^{27}$ Kurset ishin të shumëllojshme dhe organizoheshin në kurse për luftën kundër analfabetizmit, për mësimin e gjuhës shqipe, për gjysmë analfabeta, për gra, për të rritur dhe kurse profesionale. ${ }^{28}$ Krahas kurseve për të rritur të hapura në klasat shkollore, një numër i madh kursesh u hap edhe nëpër medresetë e disa qyteteve në Kosovë ku ndër të tjera spikat ajo e Gjilanit. Me mbështetjen e madhe të nacionalisteve, Mulla Idriz Gjilanit dhe Ilmi Kallabës, jo vetëm që kurset për mësimin e gjuhës shqipe patën sukses, por ata organizuan dhe një kurs tremujor në gjuhën shqipe për hoxhallarët $\mathrm{e}$ Anamoravës. ${ }^{29}$

Kurset për të rritur zakonisht zhvilloheshin në mbrëmje. Gjithashtu kishte

23 Petrika Thëngjilli, Aspekte të panjohura të veprimtarisë pedagogjike të Todi Dhramës në: "Studime Albanologjike" Universiteti i Tiranës, Fakulteti Histori-Filologji, 2002/1, f. 78.

24 Po aty.

25 Fatmira Rama, Dukuri arsimore gjatë Luftës së Dytë Botërore në Shqipëri, Tiranë: ArgetaLMG, 2005,f. 79.

26 AQSH F. 410, D. 73. V. 1944, f. 11 - 12.

27 Abdylaziz Veseli, Shkollat dhe arsimi shqip në prefekturën e Prishtinës gjatë periudhës 1941-1944 vëll. II, Gjilan:Pika 5 A, 2003, f. 317.

28 Po aty.

29 Po aty. F. 325-327. 
një vijueshmëri të rregullt të popullsisë. Në Prizren, kurset zhvilloheshin në godinën e shkollës dhe popullsisë i bëhej thirrje që të mos mungonin, pasi jo vetëm mësohej dhe edukohej, por njëkohësisht cilësohej si një detyrë kombëtare. ${ }^{30}$ Nisma për luftën kundër analfabetizmit e cilësuar me të drejtë si një detyrë kombëtare, po jepte frytet e veta pak nga pak. Në qytetet kryesore filluan organizimet e grupeve të ndryshme intelektuale dhe ngritja e qendrave artistike si themelimi i shtëpisë "Naim Frashëri” në Tetovë, me degë të muzikës, sportit dhe një biblioteke.

Kjo qendër kishte të anëtarësuar një numër të madh të rinjsh. ${ }^{31}$ Krahas kësaj kemi formimin e grupit intelektual "Le të punojmë" në Pejë, "Rinia nacionaliste në mbrojtje të kufinjve” në Prizren etj. Prizreni është një nga qendrat më të zhvilluara nga ana intelektuale në këtë periudhë. Ka një numër të madh të shfaqjeve teatrale, të konferencave për shkrimtarë të njohur, konferenca letrare dhe të gjitha këto pasqyroheshin në numrat e gazetës "Lidhja e Prizrenit". ${ }^{32}$

Gjatë vitit shkollor 1943-1944 shkollat funksionuan në përgjithësi, pasi u morën vendime për hapjen e disa shkollave të reja dhe u dërguan në to libra shkollorë dhe jashtëshkollorë. ${ }^{33}$ Por pati një ulje të numrit të shkollave dhe të nxënësve, pasi trazirat që përfshinë Kosovën në këtë periudhë patën dhe ndikimin e tyre. ${ }^{34}$

Dërgesa e librave shkollorë dhe jashtëshkollorë në Kosovë cilësohej si një çështje që kërkon vëmendje të madhe duke parë ecurinë e procesit mësimor te fëmijët, sidomos gjatë vitit shkollor 1943-1944 ku arsimi ishte shumë më i zhvilluar dhe ishte konsoliduar në pjesën më të madhe të territorit. Zhvillimi i arsimit dhe kulturës në tokat e liruara ishte padyshim nje element i fuqishëm i zgjidhjes së çështjes kombëtare. Puna e mësuesve në Troje ishte absolutisht me shumë peshë. Mbarimi i Luftës së Dytë Botërore do ta gjente Kosovën me një sistem arsimor, kryesisht në gjuhën shqipe, me 278 shkolla fillore dhe 11 shkolla të mesme. Administrata komuniste jugosllave, do të dëbonte nga arsimi mbi 700 mësues duke i shpallur armiq, u kalua kështu në sulm total ndaj gjuhës dhe kulturës shqiptare. ${ }^{35}$

30 "Shpalle", Gazeta "Lidhja e Prizrenit", 20 Mars 1944, f. 1.

31 "Themelimi i Shtëpisë "Naim Frashëri" në Tetovë", Gazeta Lidhja e Prizrenit, 14 Maj 1944, f. 9.

32 Po aty.

33 Fatmira Rama, Dukuri, f. 79-80.

34 Abdylaziz Veseli, Shkollat, f. 469.

35 Poaty. 